\title{
Geothermal power plants with improved environmental performance: assessment of the potential for an Italian site
}

\author{
Daniele Fiaschi ${ }^{*}$, Martina Leveni ${ }^{2}$, Giampaolo Manfrida ${ }^{1}$, Barbara Mendecka ${ }^{1}$, and Lorenzo Talluri ${ }^{1}$ \\ ${ }^{1}$ Department of Industrial Engineering, University of Florence, Firenze, Italy \\ ${ }^{2}$ Department of Chemical Engineering and Clean Energy Research Center, University of South Florida, Tampa, FL, USA
}

\begin{abstract}
Geothermal energy is a clean resource, which could significantly contribute to the reduction of greenhouse and other gas emissions by replacing fossil fuels for power generation. In many geothermal sites, the resource contains substantial Non-Condensable Gases (NCGs: CO2 and contaminants), whose emissions can be limited to developing power plant schemes suitable for complete resource reinjection. Organic Rankine or other closed-loop cycles are definitely favored in this light. This work investigates a solution for complete NCG reinjection in the liquid-dominated reservoir conditions typical of the Monte Amiata area (Italy), referring to the specific site of Torre Alfina (IT) which presents a specific attractiveness because of its high pressurization. The solution considered avoids flashing the resource and thus presents an appealing environmental performance. The power plant models include energy and exergy balances, as well as exergoenvironmental analysis. The overall environmental performance is evaluated by a simplified (preliminary) Life Cycle Analysis (LCA). Different solutions are compared, considering the possibility of sub- or supercritical power cycles.
\end{abstract}

\section{Introduction}

The steady development of geothermal energy, which is acknowledged as a renewable resource, capable of providing electricity and heat at favorable economic conditions and with limited environmental impact, has led to investigating resource conditions which were not appealing in the past. These are often medium- or lowenthalpy hydrothermal resources, often with substantial contents of non-condensable gases and salts. These conditions are difficult to exploit with traditional technologies, which consist today of applying a flash (usually in a surface separator) determining the production of a stream of saturated steam. In flash systems, because of the low solubility of salts in the vapor phase, the steam conditions allow direct expansion in a turbine; however, the liquid brine is rich in salts and this often entails precipitation of salts and scaling of equipment. In order to avoid this issue, it is often necessary to raise the operating temperature (and pressure) of the separator, thereby determining a limited utilization of the resource. Moreover, if NCGs are present in the resource, these are expanded together with the steam reaching very low pressures at turbine discharge; this NCG stream must be recovered from the vacuum condenser and compressed: usually it is vented to the atmosphere, thereby determining emissions of greenhouse gases $\left(\mathrm{CO}_{2}\right.$ and $\left.\mathrm{CH}_{4}\right)$ and other contaminants. Within these, specific concerns are rose by the presence of $\mathrm{H}_{2} \mathrm{~S}$ and $\mathrm{Hg}[1,2]$. With reference to contaminants, current geothermal plants in Italy apply advanced emission treatment through chemical scrubbing and adsorption (AMIS $\mathbb{R},[3]$ ), effectively removing $\mathrm{H}_{2} \mathrm{~S}, \mathrm{Hg}$, and $\mathrm{NH}_{3}$; however, the issue of greenhouse emissions remains unsolved with the current technology, leading to documented values averaging $122 \mathrm{mg} / \mathrm{kWh}$ but with a relevant spread among different plants $[4,5]$.

The reasons above have led several researchers to explore the possibility of developing geothermal power plants with complete reinjection, including NCGs as well as the liquid brine. Among the solutions, already object of demonstration projects, two-phase reinjection in the reservoir [6] or $\mathrm{CO}_{2}$ mineralization [7] can be applied - both solutions taking advantage of progress in the Oil\&Gas [8] or in the Carbon Capture and Storage (CCS) fields.

\section{Torre Alfina (IT) Site}

The Torre Alfina geothermal site is one of the most documented in Italy, thanks to an extensive exploration campaign performed by ENEL in the 1970-80s. At that

\footnotetext{
* Corresponding author: daniele.fiaschi@unifi.it
} 
time, the resource was recognized as a difficult one to be utilized through traditional flash technology, mainly because of the relevant presence of NCGs (about $2 \%$ by weight $\mathrm{CO}_{2}, 0.2 \% \mathrm{H}_{2} \mathrm{~S}$ ) [9-11]. The resource data are reported in the Italian geothermal resource database $[12$, 13]. The Torre Alfina site consists of a water-dominated reservoir at high pressure (44 bar) and medium temperature $\left(140^{\circ} \mathrm{C}\right)$. Through a combination of several wells ( 5 production wells and 4 reinjection wells), it should be possible to extract at least $300 \mathrm{~kg} / \mathrm{s}$ of geothermal brine, allowing the recovery of the reservoir thermal equilibrium after the production processes, and avoiding possible thermal interferences among production and reinjection wells. Therefore, the conditions are in line with the Italian laws [14] to allow special permission for the pilot realization of a $5 \mathrm{MWe}$ power plant (up to this power, permissions for difficult geothermal resources - medium/low temperature with large NCG content) are issued on a national basis rather than at regional level [15]. The geothermal reservoir is mainly composed of carbonates of the Tuscan Complex and the caprock is constituted by the Volcanic complex, the Neoautochtonous, and Ligurian complexes.

\section{Geothermal project specifications, model of power plant and variants}

The geothermal project specifications were taken from the repository of the Italian Ministry of Environment and Protection of Land and Sea [15]. A general layout including the brine and the ORC loop is shown in Figure 1. Following directives by the Italian Ministries of Industry and Environment, and in order to avoid scaling problems, the brine should be reinjected at $\mathrm{T}>70^{\circ} \mathrm{C}$. The brine loop is conceived with a submersible pump placed at $400-600 \mathrm{~m}$ depth; this should allow avoiding two-phase flash in the production well. The pump pressurizes the brine at about 136 bar, which drops to 44 bar as the ground level is reached. This pressure is enough to avoid the release of NCGs when the resource is cooled in the main heat exchanger (Main HE). The original design of the power plant uses isobutane as a working fluid, which is suitable for the temperature range of the resource. The main data specifications and auxiliary data for setting up the power plant model (including resource and ORC binary section) are collected in Table 1.

Table 1. Power plant simulation settings.

\begin{tabular}{ccc}
\hline & Subcritical & Supercritical \\
\hline $\mathrm{T}_{30}\left[{ }^{\circ} \mathrm{C}\right]$ & 140 & 140 \\
$\mathrm{P}_{30}[\mathrm{bar}]$ & 44 & 44 \\
$\dot{\mathrm{m}}_{30}[\mathrm{~kg} / \mathrm{s}]$ & 313 & 218 \\
$\mathrm{CO}_{2}[\mathrm{w} \%]$ & 2 & 2 \\
$\mathrm{Fluid}$ & isobutane & $\mathrm{R} 1234 \mathrm{yf}$ \\
$\mathrm{P}_{6}[\mathrm{bar}]$ & 14.82 & 41.98 \\
$\mathrm{~T}_{6}\left[{ }^{\circ} \mathrm{C}\right]$ & 85 & 120 \\
$\dot{\mathrm{m}}_{6}[\mathrm{~kg} / \mathrm{s}]$ & 269 & 426 \\
$\eta_{\mathrm{T}}, \eta_{\mathrm{P}}[-]$ & $0.87,0.8$ & $0.87,0.8$ \\
$\Delta \mathrm{TPP}_{\mathrm{PP}}\left[{ }^{\circ} \mathrm{C}\right]$ & 5 & 5 \\
\hline
\end{tabular}

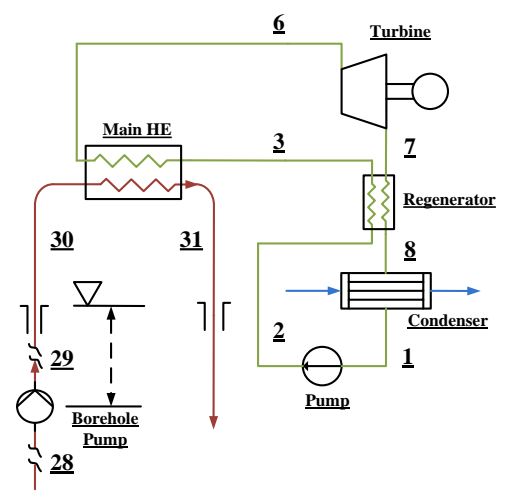

Fig. 1. General layout of power plant (brine and ORC circuits).

Two cases were considered: the original design, with a subcritical ORC cycle, and an advanced one with a supercritical ORC using R1234yf. The supercritical solution allows better matching of the heat capacities between the working fluid and the geothermal brine. The borehole pump and the Main HE are challenging components due to the expected size and high operating pressure. However, the solution without resource flash replaces the separator and completely avoids the release of NCGs to the environment (which would require complex equipment for the reinjection). Moreover, it is favored by the high pressurization of the reservoir.

\section{Energy and exergy modeling}

Mass, energy and exergy balances were set up following a consolidated practice for the analysis of power plants [16]. The organic fluids properties were modeled using high-accuracy equations of state (reduced Helmholtz free energy), available within the simulation environment [17], while the geothermal brine was modeled through specific libraries available in Unisim ${ }^{\circledR}$ or TREND 3.0 [18]. Special attention was given to the Main HE model in the supercritical case: actually, the fluid on both sides undergoes a variation of the constant-pressure specific heat. Consequently, the point of minimum temperature difference (pinch point temperature difference, $\Delta \mathrm{T}_{\mathrm{pp}}$, is applied) is unknown and must be sought iteratively, by setting up a procedure which divides the Main $\mathrm{HE}$ in a large number of subsections.

For exergy calculations, the reference conditions were set to the environmental ones $\left(25^{\circ} \mathrm{C}, 101325 \mathrm{~Pa}\right)$; however, all exergy destructions were calculated with in/out balances across the components. The exergy loss due to the reinjection of the brine was not considered, because this is an external constraint imposed by regulations. Anyhow, the above-mentioned effect on reduction of salts precipitation (and thus scaling) due to cooling of the geothermal resource, might be helpful in opening the way to an appreciable reduction of the minimum reinjection temperature imposed by these regulations. On the other hand, the exergy loss due to heat rejected to the environment by the closed-loop cooling tower was fully included, as it depends on the technical solutions adopted for releasing the cooling load to the environment. 


\section{Life Cycle Assessment and Exergo- Environmental analysis}

After the energy and exergy analysis, the environmental performance of the power plant is evaluated. On the whole, this is done using Life Cycle Assessment (LCA) [19, 20]. The Life Cycle Inventory (LCI) was built using the EcoInvent 3.6 database [21], accessed through OpenLCA 1.10.1 [22]. ReCiPe 2016 Endpoint $(\mathrm{H})$ (hierarchist perspective impact assessment with normalization and weighting set: Europe ReCiPe $\mathrm{H})$ method was used to quantify the single score environmental impact of each component of the system [23]. The functional unit was assumed as $1 \mathrm{MWh}$ of electricity. The analysis is run as a cradle-to-gate LCA. Therefore, it includes the construction and operational phases. In fact, it is known that construction (with specific reference to the drilling of the wells) represents a relevant phase of the Life Cycle Impact of a geothermal power plant [24].

The Exergo-Environmental analysis (EEvA) applies the same workflow of Exergo-Economic model [25], using the environmental costs of components through a component-level disaggregation of the LCI and calculating the build-up of the environmental cost along the power plant. Regarding the wells and machinery equipment, data about the specific material consumption used LCA process were collected from the environmental assessments provided by the [15]. The main formulas for EEvA are presented in Table 2.

Table 2. Main relationships for EEvA analysis analysis.

\begin{tabular}{c}
\hline EEvA analysis \\
\hline EEvA stream impact rate \\
$\dot{\mathrm{B}}_{\mathrm{j}}=\mathrm{b}_{\mathrm{j}} \cdot \dot{\mathrm{Ex}}_{\mathrm{j}}$ \\
Component environmental impact balance \\
$\sum \dot{B}_{j, k, i n}+\dot{Y}_{k}=\sum \dot{B}_{j, k, \text { out }}$ \\
Component-related environmental impact rate \\
$\dot{Y}_{k}=\dot{Y}_{C O}+\dot{Y}_{O M}+\dot{Y}_{D I}$ \\
Component exergo-environmental factor \\
$f_{d, k}=\frac{\dot{Y}_{k}}{\dot{B}_{D, k}+\dot{Y}_{k}}$ \\
\hline
\end{tabular}

\section{Results}

\subsection{Energy and exergy modeling}

The performance assessment of the ORC pilot plant of Castelgiorgio - Torrealfina site is carried out under EES environment [17]. The design configuration of the ORC is a subcritical saturated vapor cycle working with isobutane, as shown in Figure 2a. Due to the specific geothermal resource (sub-cooled liquid), it is also interesting to consider a super-critical configuration of the power plant, because this solution can achieve a better match between the T-Q curves of the geothermal brine and of the ORC working fluid. Due to the low temperature of the resource, it is not possible to propose a supercritical cycle with isobutane as working fluid (the critical temperature being $134.7^{\circ} \mathrm{C}$ for this fluid). Thus, R1234yf was selected as a working fluid thanks to its lower critical temperature $\left(94.7^{\circ} \mathrm{C}\right)$. Figure $2 \mathrm{~b}$ displays the T-s chart of the supercritical cycle.

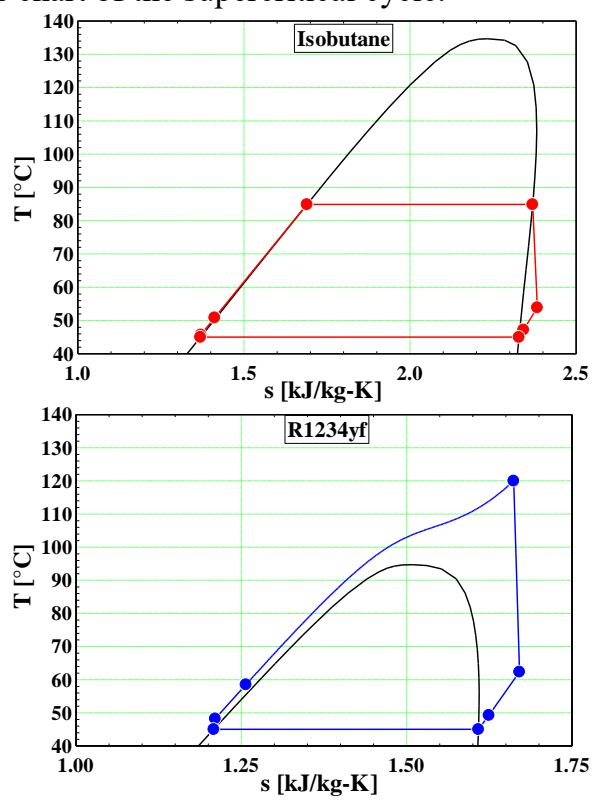

Fig. 2. Thermodynamic cycles: (a) subcritical isobutane (b) supercritical R1234yf.

The main performance parameters are summarized in Table 3. It can be noticed that the supercritical cycle allows an increase of both the thermodynamic and exergy efficiencies of the system. Indeed, the better matching of the $\mathrm{T}-\mathrm{Q}$ curves into the main heat exchanger results in lower irreversibilities due to heat transfer, and higher temperature at the turbine inlet. More effective use of the geothermal brine is achieved with the supercritical cycle, as shown in Figure 3: the total heat required by the power plant in order to produce $5 \mathrm{MWe}$ is nearly $30 \%$ lower, and this directly reflects in a lower impact on the geothermal resource, and in a potential increase of the production lifetime of the geothermal project.

Table 3. Performance parameters of ORC power plant.

\begin{tabular}{ccc}
\hline & Subcritical & Supercritical \\
\hline$\eta_{\mathrm{ORC}}[\%]$ & 8.4 & 10.8 \\
$\eta_{\mathrm{I}}[\%]$ & 5.3 & 7.6 \\
$\eta_{\mathrm{II}}[\%]$ & 22 & 31.6 \\
$\mathrm{~W}_{\mathrm{T}}[\mathrm{kW}]$ & 8216 & 8429 \\
$\mathrm{~W}_{\mathrm{P}}[\mathrm{kW}]$ & 562.8 & 1582 \\
$\mathrm{~W}_{\mathrm{BHP}}[\mathrm{kW}]$ & 2653 & 1847 \\
$\dot{\mathrm{Q}}_{\mathrm{GEO}}[\mathrm{kW}]$ & 90814 & 63222 \\
\hline
\end{tabular}

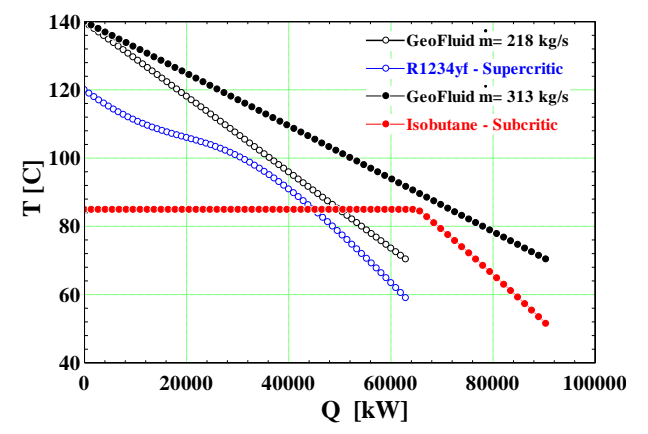

Fig. 3. Composite curves (Temperature - Heat) of the main geothermal heat exchanger for the subcritical (Isobuthane) and supercritical (R1234yf) power cycles 
A straightforward graphical representation of the inefficiencies of energy conversion systems is provided by exergy Grassmann diagrams. Figure 4 puts in evidence the increase in the exergy efficiency of the supercritical cycle, resulting from a significant reduction of the exergy destruction in the $\mathrm{HE}_{\mathrm{GEO}}$. This is, in both cases, the largest exergy destructive, component, while high losses are present both at the condenser and the BH pump wells.
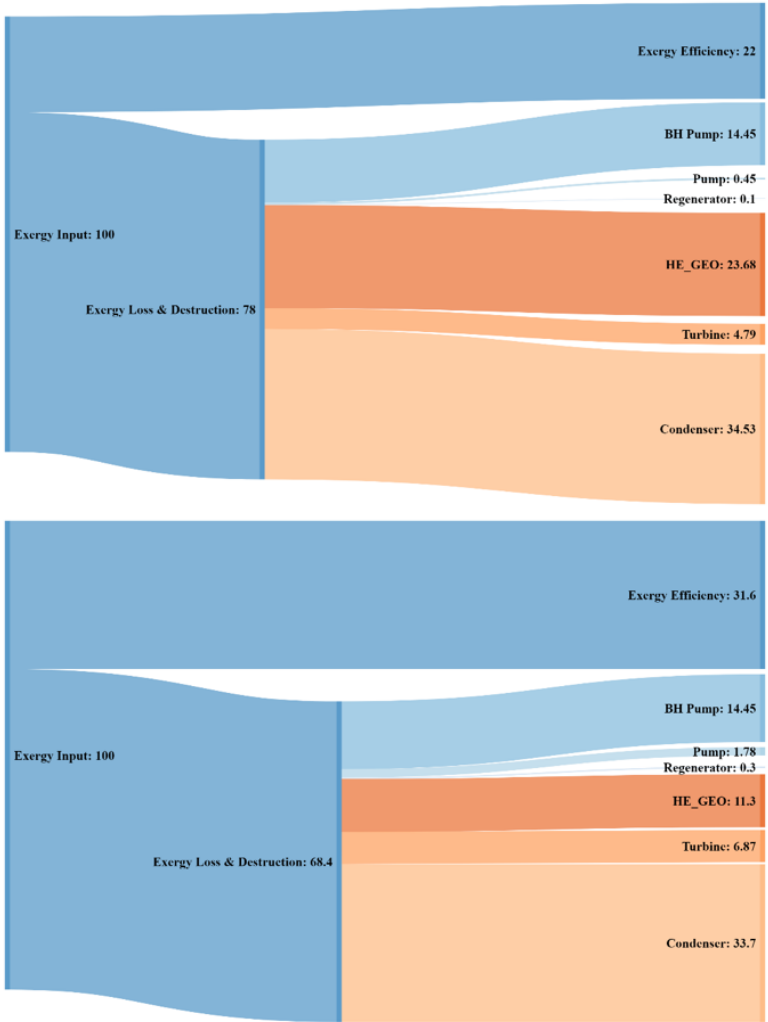

Fig. 4. Grassmann diagram of (a) subcritical and (b) supercritical cycles.

\subsection{Life Cycle Assesment and Exergo- Environmental analysis}

Figure 5 presents a comparison of ReCiPe 2016 single scores of high voltage electricity produced in the two analyzed geothermal power cycles. It can be noticed that the subcritical power cycle is characterized by a slightly higher impact value $(3.4 \%)$ compared to the supercritical case. In fact, the subcritical cycle has a larger condenser and cooling system that significantly contributes $(7.7$ and $4.7 \%$ for sub- and supercritical cycles, respectively) to the final impact. For both cases, the highest contribution to the total impact value (77.9 and $77.5 \%$, for sub and supercritical cycles, respectively) is due to the geothermal wells' construction. Regarding the environmental impact of the working fluid, its contribution to the total impact is negligible; in absolute terms, isobutane is characterized by a lower impact. Therefore, the working fluid contribution is smaller for the subcritical cycle, accounting for $0.7 \%$ of the total impact. The contribution of the power cycle machinery is significant for both cases (around $17.5 \%$ ), with the condenser being the main responsible.

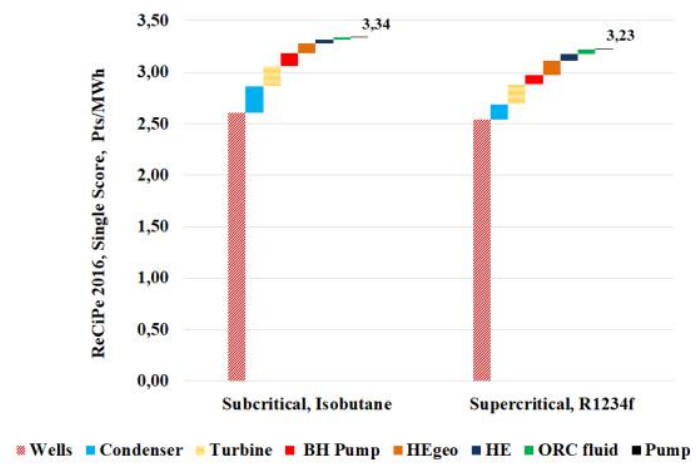

Fig. 5. Comparison of ReCiPe Single Score environmental impacts of electricity produced in the geothermal plants

Figure 6 compares ReCiPe 2016 single scores of high voltage electricity produced in the two analyzed power cycles with those of other renewable energy systems $[26,27]$. As can be observed, electricity from binary geothermal power plants has a more favorable overall environmental performance compared to other renewable energy sources. Previous literature studies comparing different electricity technologies, report the value of the environmental impact of electricity produced with geothermal power plants in the range between wind and photovoltaic systems for the most relevant LCA categories [24]. However, these studies were referred to powerplants without NCG sequestration: thus, it is not surprising that the overall environmental performance of the present case study is superior. Tables 4 and 5 report the results of exergo environmental analysis.

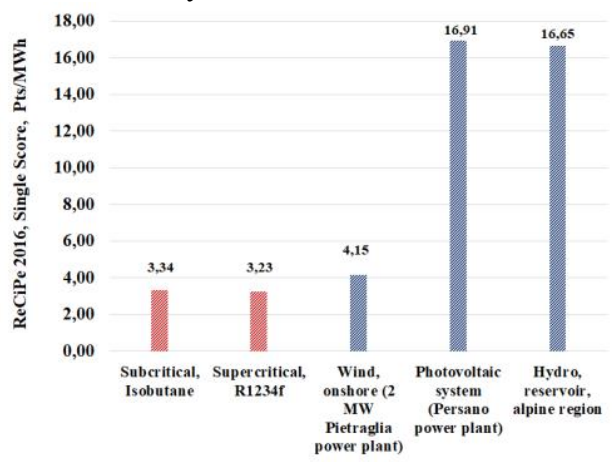

Fig. 6. Comparison of ReCiPe Single Score environmental impacts of electricity produced in the geothermal plants and other renewable - based power systems

Table 4. Exergoenvironmental results for the subcritical isobutane cycle.

\begin{tabular}{cccccc}
\hline & $\begin{array}{c}\text { ReCiPe.201 } \\
\text { 6 Single } \\
\text { Score } \\
\text { (Pts) }\end{array}$ & $\begin{array}{c}\dot{\boldsymbol{Y}}_{\boldsymbol{k}} \\
(\mathbf{m P t s} / \mathbf{s})\end{array}$ & $\begin{array}{c}\dot{\boldsymbol{B}}_{\boldsymbol{D} \boldsymbol{k}} \\
(\mathbf{m P t s} / \mathbf{s})\end{array}$ & $\begin{array}{c}\boldsymbol{f}_{\boldsymbol{D} . \boldsymbol{k}} \\
(-)\end{array}$ & $\begin{array}{c}\boldsymbol{r}_{\boldsymbol{D} . \boldsymbol{k}} \\
(-)\end{array}$ \\
\hline BH Pump & 225141 & 0.282 & 0.252 & 0.528 & 0.247 \\
Pump & 7427 & 0.010 & 0.096 & 0.093 & 0.243 \\
HE & 66089 & 0.082 & 0.018 & 0.823 & 0.345 \\
HEgeo & 162746 & 0.232 & 1.259 & 0.155 & 0.327 \\
Turbine & 358742 & 0.453 & 0.847 & 0.348 & 0.203 \\
Condenser & 460351 & 0.584 & 3.374 & 0.148 & - \\
\hline
\end{tabular}


Table 5. Exergoenvironmental results of the supercritical R1234yf cycle.

\begin{tabular}{cccccc}
\hline & $\begin{array}{c}\text { ReCiPe } \\
\text { 2016. } \\
\text { Single } \\
\text { Score } \\
\text { (Pts) }\end{array}$ & $\begin{array}{c}\dot{\boldsymbol{Y}}_{\boldsymbol{k}} \\
(\mathbf{m P t s} / \mathbf{s})\end{array}$ & $\begin{array}{c}\dot{\boldsymbol{B}}_{\boldsymbol{D} . \boldsymbol{k}} \\
(\mathbf{m P t s} / \mathbf{s})\end{array}$ & $\begin{array}{c}\boldsymbol{f}_{\boldsymbol{D} \boldsymbol{k} \boldsymbol{k}} \\
(-)\end{array}$ & $\begin{array}{c}\boldsymbol{r}_{\boldsymbol{D} . \boldsymbol{k}} \\
(-)\end{array}$ \\
\hline BH Pump & 163956 & 0.208 & 0.202 & 0.508 & 0.237 \\
Pump & 21046 & 0.033 & 0.297 & 0.099 & 0.243 \\
HE & 125536 & 0.157 & 0.035 & 0.816 & 0.289 \\
HEgeo & 255939 & 0.358 & 0.668 & 0.349 & 0.202 \\
Turbine & 373582 & 0.489 & 0.951 & 0.340 & 0.195 \\
Condenser & 284945 & 0.382 & 4.091 & 0.085 & \\
\hline
\end{tabular}

As can be observed, for the subcritical cycle, the highest total environmental impact at the component level $\left(\dot{B}_{D, k}+\dot{Y}_{k}\right)$ is due to the condenser contributing more than $50 \%$ to the total component related impact (3.06 $\mathrm{mPts} / \mathrm{s}$ and $4.47 \mathrm{mPts} / \mathrm{s}$, for the subcritical and supercritical power cycles, respectively). Also, the turbine, the main heat exchanger and the borehole pump present relevant $(>10 \%)$ scores $\left(\dot{B}_{D, k}+\dot{Y}_{k}\right)$, in the range from 0.4 to $1.49 \mathrm{mPts} / \mathrm{s})$. The higher the total environmental impact rate, the larger the influence of the component on the overall system; depending on the share of $\dot{Y}_{k}$ or $\dot{B}_{D, k}$, improvements of performance can be recommended for components having low $\dot{Y}_{k}$ and high $\dot{B}_{D, k}$ (Condenser, Turbine, HEgeo), while improvements regarding the design/materials economy can be recommended for components which has low $\dot{B}_{D, k}$ and a high $\dot{Y}_{k}$ (e.g. regenerative heat exchangers). Indeed, the condenser groups exergy destruction and exergy loss, with relevant flows of heat and exergy when compared to the reference state and stands thus as the component deserving the largest attention for the improvement of environmental performance.

\section{Conclusions}

The Torre Alfina geothermal site is a waterdominated reservoir at high pressure (44 bar) and medium temperature $\left(140^{\circ} \mathrm{C}\right)$, where the resource has a moderate content of $\mathrm{CO}_{2}(2 \%)$, which is found as dissolved in the liquid phase because of the high pressure level. These conditions are in line with Italian laws, allowing special permissions for the realization of a pilot-size power plant $\left(5 \mathrm{MW}_{\mathrm{e}}\right)$, and suggested to develop a binary ORC powerplant using a high-pressure borehole pump and main brine-ORC working fluid heat exchanger (44 bar), avoiding flash and release of NCGs to the environment.

The performance of the power cycle is analyzed by means of mass/energy, exergy, LCA and exergoenvironmental models. The power plant must be fed by a large number of wells, considering the moderate thermodynamic value of the liquid resource and the large flow rate ( 5 production and 4 reinjection wells). The supercritical solution has a higher efficiency, thus allowing a reduced consumption of geothermal resource for the fixed $5 \mathrm{MW}$ power production. It allows smaller equipment (HEgeo) and the possibility of a longer lifetime of the geothermal reservoir. The exergy analysis confirms these results, identifying the $\mathrm{HE}_{\mathrm{GEO}}$, the condenser and the $\mathrm{BH}$ pump as the most critical components.

From an economic point of view the crucial issue is not the power plant configurations, but the large cost of the numerous wells (9), which would double the expected LCOE compared to the typical values of traditional dry-steam or flash geothermal power plants. Anyway, this LCOE may still be attractive in the light of the contributions allowed for power plants operating on such difficult resources.

The LCA confirms that geothermal power plants with complete NCG reinjection are among the cleanest renewable energy technologies, with an edge even over wind energy. Again, the largest part of the environmental impact comes from the activity of well drilling in the construction phase, followed by the borehole pump; the surface powerplant equipment represents a minor share.

The exergo-environmental analysis confirms that the components deserving improvements in terms of environmental performance are the condenser, the turbine and the main heat exchanger; however, the improvement should focus in some cases on design/materials economy and in others on thermodynamic performance, depending on the relevance of $\dot{Y}_{k}$ or $\dot{B}_{D, k}$.

\section{Acknowledgements}

The LCA study was performed thanks to inclusion of Torre Alfina as one of the simplified test cases of the H2020 GEOENVI (Grant Agreement $n^{\circ}$ 818242). Knowledge of mixture properties and application of the exergo-environmental approach to geothermal power plants benefits from research done within the H2020 GECO project (Grant Agreement n 818169).

\section{Nomenclature}

Symbols and acronyms

$\dot{\mathrm{B}}$ Exergoenvironmental impact factor, $\mathrm{mPts} / \mathrm{s}$

$\dot{\mathrm{m}}$ Mass flow rate, $\mathrm{kg} / \mathrm{s}$

Q $\quad$ Heat rate, $\mathrm{kW}$

$\dot{\mathrm{W}}$ Power, $\mathrm{kW}$

$\dot{\mathrm{Y}}$ Environmental impact factor, $\mathrm{mPts} / \mathrm{s}$

BH Borehole

EEvAExergo-environmental analysis

Ext Exergy, $\mathrm{kW}$

HE Heat exchanger

LCI Life cycle inventory

$\mathrm{P}$ Pressure, bar

T Temperature, ${ }^{\circ} \mathrm{C}$

$\mathrm{X}$ Functional unit

y Molar fraction

s Entropy, $\mathrm{kJ} / \mathrm{kg} \cdot \mathrm{K}$

Greek letters

$\Delta \mathrm{T} \quad$ Temperature difference, ${ }^{\circ} \mathrm{C}$

$\eta \quad$ Efficiency

$\eta \quad$ Efficiency

Subscripts

$0 \quad$ Reference state

$1,2, .$. State point

D Destruction

GEO Geothermal brine

I First law

II Second law 


$\begin{array}{ll}\mathrm{j} & \text { Stream } \\ \mathrm{k} & \text { Component } \\ \text { ORC } & \text { Organic Rankine Cycle } \\ \mathrm{P} & \text { Pump } \\ \mathrm{Pp} & \text { Pinch Point } \\ \mathrm{T} & \text { Turbine }\end{array}$

\section{References}

1. Kagel, A., Bates, D., Gawell, K., A Guide to Geothermal Energy and the Environment, (2007), Geothermal Energy Association www.geo-energy.org.

2. Rice, K.M., Walker, E.M., Wu, M., Gillette, M., Blough, E.: Environmental Mercury and Its Toxic Effects, Journal of Preventive Medicine and Public Health, 47, (2014), 7483.

3. Baldacci A., Mannari M., Sansone F.: Greening of Geothermal Power: An Innovative Technology for Abatement of Hydrogen Sulphide and Mercury Emission, Proceedings, World Geothermal Congress 2005, Antalya, Turkey, (2005).

4. Eberle, A., Heath, G., Nicholson, S., Carpenter, A.: Systematic Review of Life Cycle Greenhouse Gas Emissions from Geothermal Electricity, NREL, (2017), (www.nrel.gov/publications).

5. Bruscoli, L, Fiaschi, D., Manfrida, G., Tempesti, D., Improving the Environmental Sustainability of Flash Geothermal Power Plants-A Case Study, Sustainability, $7, \quad$ (2015), 15262-15283, doi:10.3390/su71115262.

6. Shafaei M.J., Abedi J., Hassanzadeh H., Chen Z.: Reverse gas-lift technology for $\mathrm{CO}_{2}$ storage into deep saline aquifers, Energy, 45, (2012), 840-849.

7. Snæbjörnsdóttir S.O., Orlkers E.H., Mesin K., Aradóttir E.S., Dideriksen K., Gunnarsson I., Gunnlaugsson E., Matter J.M., Stute M., Gislason S.R.: The chemistry and saturation states of subsurface fluids during the in situ mineralisation of $\mathrm{CO}_{2}$ and $\mathrm{H}_{2} \mathrm{~S}$ at the CarbFix site in SWIceland, International Journal of Greenhouse Gas Control, 58, (2017), 87-102.

8. Guo B., Li G., Song J., Li J.: A feasibility study of gas-lift drilling in unconventional tight oil and gas reservoirs, Journal of Natural Gas Science and Engineering, 37, (2017), 551-559.

9. Buonasorte, G., Cataldi, R., Ceccarelli, A., Costantini, A., D’Offizi, S., Lazzarotto, A.: Ricerca ed esplorazione nell'area geotermica di Torre Alfina (Lazio-Umbria), Boll.Soc.Geol.It., (1988), 265-337.

10. Buonasorte, G., Pandeli, E., Fiordelisi, A.: The Alfina 15 well: deep geological data from Northern Latium (Torre Alfina geothermal area), Boll.Soc.Geol.It., (1991), 823831.

11. Regione Umbria, Università di Perugia: Studio delle potenzialità geotermiche del territorio regionale umbro Report finale, (2013).

12. DGS-UNMIG, M. dello sviluppo economico: Pozzi geotermici, (2018a), http://unmig.mise.gov.it/unmig/geotermia/pozzi/pozzi.as $\mathrm{p}$ (accessed 12.25.18).

13. DGS-UNMIG, M. dello sviluppo economico: Inventario delle risorse geotermiche nazionali, (2018b), http:/unmig.sviluppoeconomico.gov.it/unmig/geotermia/ inventario/inventario.asp (accessed 12.25.18).

14. DGS-UNMIG, M. dello sviluppo economico: Ricerca di risorse geotermiche finalizzata alla sperimentazione di Impianti Pilota, https://unmig.mise.gov.it/index.php/it/dati/risorsegeotermiche/ricerca-di-risorse-geotermiche-finalizzataalla-sperimentazione-di-impianti-pilota (accessed 5.9.19).

15. Italian Ministry of the Environment and Protection of
Land and Sea : Impianto pilota geotermico denominato "Torre Alfina", Acquapendente (VT) - VAS - VIA - AIA, (2018), http://www.va.minambiente.it/itIT/Oggetti/Info/1566 (accessed 12.25.18).

16. Bejan A., Tsatsaronis G., Moran M.J.: Thermal Design and Optimization, John Wiley \& Sons, (1996).

17. Klein S.A., Nellis G.F.: Mastering EES, f-Chart software, (2012).

18. Colucci V., Fiaschi D., Leveni M., Manfrida G., Talluri L.: Thermodynamic model of geothermal resources for low-medium temperature energy conversion process optimization, Chemical Engineering Transactions, 76, (2019).

19. ISO (2006a). ISO 14040: Environmental management: Life-cycle assessment: Principles and framework. International Organization for Standardization, Geneva, Switzerland, available at http://www.iso.org (last accessed on $12 / 07 / 2019)$.

20. ISO (2006b). ISO 14044: Environmental management: Life-cycle assessment: Requirements and guidelines. International Organization for Standardization, Geneva, Switzerland. available at http://www.iso.org (last accessed on 12/07/2019).

21. Wernet G., Bauer C., Steubing B., Reinhard J., MorenoRuiz E., Weidema, B.: The ecoinvent database version 3 (part I): overview and methodology, The International Journal of Life Cycle Assessment, 21, (2016), 1218-1230.

22. Di Noi C., Ciroth A., Srocka M.: OpenLCA 1.7, Comprehensive User Manual, GreenDelta GmbH, Berlin, Germany, (2017)

23. Huijbregts M.A.J., Steinmann Z.J.N., Elshout P.M.F., Stam G., Verones F., Vieira M.D.M., Hollander A., Zijp M., Van Zelm R., ReCiPe 2016, A harmonized life cycle assessment method at midpoint and endpoint level, Report, National Institute for Public Health and the Environment, The Netherlands, (2016).

24. Asdrubali, F., Baldinelli, G., D'Alessandro, F., Scrucca, F., Life cycle assessment of electricity production from renewable energies: Review and results harmonization, Renewable and Sustainable Energy Reviews 42, (2015), 1113-1122.

25. Fiaschi D., Manfrida G., Rogai E., Talluri L.: Exergoeconomic analysis and comparison between ORC and Kalina cycles to exploit low and medium-high temperature heat from two different geothermal sites, Energy Conversion and Management, 154, (2017), 503516.

26. Trever, K., Bauer, C.: Life cycle inventories of electricity generation and power supply in version 3 of the ecoinvent database-part I: electricity generation, The International Journal of Life Cycle Assessment, 21(9), (2016a), 12361254.

27. Trever, K., Bauer, C.: Life cycle inventories of electricity generation and power supply in version 3 of the ecoinvent database-part II: electricity markets, The International Journal of Life Cycle Assessment, 21(9), (2016b), 1255-1268 